БАКУШЕВ Валерий Владимирович - доктор политических наук, профессор; заведующий кафедрой парламентаризма и межпарламентского сотрудничества Института государственной службы и управления Российской академии народного хозяйства и государственной службы при Президенте РФ (119571, Россия, г. Москва, пр-кт Вернадского, 82; la.kolesnikova@igsu.ru)

ПОНЕДЕЛКОВ Александр Васильевич - доктор политических наук, профессор; заведующий кафедрой политологии и этнополитики Южно-Российского института управления - филиала Российской академии народного хозяйства и государственной службы при Президенте РФ (344082, Россия, г. Ростов-на-Дону, ул. Пушкинская 70; ponedelkov@uriu.ranepa.ru)

\title{
ПОИСК СТРАТЕГИЧЕСКОЙ СТАБИЛЬНОСТИ С УЧАСТИЕМ РОССИИ: ОТТОРЖЕНИЕ «ДВОЙНЫХ СТАНДАРТОВ» И ПОЛИТИЧЕСКОЙ ЛЖИ
}

\begin{abstract}
Аннотация. В статье отмечается, что в настоящее время актуальна проблема не только поиска, но и объяснения существующей гипертрофированной конфликтности. Продолжающееся переформатирование мировых процессов вызывает нарушение безопасности. Они обусловлены новой эрой конкуренции великих держав (на Мюнхенской конференции по безопасности 2019 г. в число сверхдержав, наряду США и Китаем, была отнесена и Россия. Признается, что без ее участия нельзя представить ни европейскую, ни мировую безопасность). Однако пока еще неустойчиво понимание, что формирующийся новый многополярный миропорядок не решает всех проблем, а только создает новую среду для их решения. Кровоточащих конфликтов не стало меньше. При этом структура политических партий в Старом Свете и новых демократиях не отражает современные интересы большинства граждан. В статье ставится проблема и раскрывается позиция автора по поиску стратегической стабильности с участием России в условиях, когда она уже вышла из ниши “униженно развивающейся» страны, стремясь войти в пятерку ведущих государств мира.
\end{abstract}

Ключевые слова: современный кризис в геополитике, молчаливая поддержка нацизма в Европе, стремление США к удержанию своего гегемонизма, раздвоение позиции в странах $E C$, усиление политических позиций России для стратегической стабильности, новый призыв к борьбе за мир, курс России на партнерство, новизна внутренней социально-экономической политики

$\mathrm{K}$ 12-летию официального дистанцирования России от либерального Запада действующая элита Европы и ее экспертное окружение попытались осмысленно подойти к оценке эволюционирования мира и ключевых политических процессов. Традиционно проводящаяся Мюнхенская конференция по безопасности в феврале 2019 г. собралась в 55-й раз - в Баварии (Германия). Она имела стремление выявить ключевые принципы динамики современного мира, учитывая правильность постановки вопросов президентом РФ В.В. Путиным еще в 2007 г. в его известной речи ${ }^{1}$.

Главным смыслом конференции все же является появление новых факторов неопределенности, к решению которых «объединенный Запад» оказался не готовым. Выросшее новое поколение политиков не способно решать существующие и грядущие проблемы, в т.ч. связанные с обострением миграционного фактора, самостоятельностью поведения без США и принятием ответственности при ломке модели «однополярного» устройства мира и появлении лож-

\footnotetext{
1 Мюнхенская встреча известных политиков и экспертов на конференции по безопасности проходила 14-15 февраля 2019 г., хотя на нее не явились рассорившиеся действующие лидеры Франции и Германии, других стран. Весной 2007 г. В.В. Путин в своей речи на конференции открыто предупредил об ущербности проводимой Западом политики по отношению к государствам, не отнесенных ими к «объединенному Западу». От имени России было объявлено, что она будет проводить самостоятельную политику и выбирать партнеров.
} 
ных обвинений по отношению к придуманным или «назначенным» врагам, к которым отнесена и Россия. Но, по меткому замечанию известного политолога Ф. Лукьянова, степень фобии на Западе по отношению к «руке Кремля» требует специалистов в сфере «не международной политики, а клинического психоанализа» 1 .

Наконец, усиливается страх перед ситуацией уходящего мирового порядка на основе либерализма как устаревшего западного центризма в политике и мышлении. Поэтому стоит «прекратить волочиться в фарватере западной мысли» 2 . Сегодня все более определенно востребован геополитически и геоэкономически более плюралистический мир. Но плюрализм здесь подразумевается не бескрайний, а с формированием двух центров притяжения - Америки и Большой Евразии.

Уточним, что в первую группу стран могут входить участники обновленной зоны торговли США-Канада-Мексика плюс Великобритания и часть других европейских государств. Вторая группа может еще дооформиться с участием Китая и России на севере большой Евразии. Но против Китая ныне и в будущем могут консолидироваться ряд региональных ведущих стран Азии ${ }^{3}$. При этом появление новых типов вооружений будет вести к понижению международной стратегической стабильности. В переходный период также может возникнуть обострение отношений внутри Евросоюза, т.е. сильнее обозначится его «рыхлость». Отношения здесь вполне могут переходить в русло усиления роли двусторонних контактов. Политическая сила (вслед за экономическим противостоянием) может «перетекать и в культурно-моральное влияние» 4 .

В этих условиях условно объединенный Запад пока не только не адаптируется к новому соотношению сил, но и не готов даже мысленно осознавать меняющийся каркас мира, формирование новой мировой системы. Навязанное «трамповской моделью» поддержание своего гегемонизма через применение «закона джунглей» связано с ложью и наполняется неприемлемыми приемами в политике, ведет к разрушению международного права. Не смог выработать ориентиры общих целей прошедший накануне Мюнхена и Давосский форум с центральной дискуссией на тему: «Глобализация 4.0: формирование глобальной архитектуры в век четвертой индустриальной революции». Форум проходил в ситуации, когда «западная либеральная бизнес-модель больше не считается примером, на который равняются остальные» 5 .

Мы исходим из той формируемой синергетической концепции, что нужен «прорыв в новую цифровую эру» и одновременно требуются «целенаправленные усилия по предотвращению умственной деградации элит (возможно и влияние цифровизации). В политике и деловых практиках должен поддерживаться приоритет предотвращения войны и проявления новой активности по защите мира. Важно обеспечивать строительство сообщества независимых, суверенных и сотрудничающих стран и народов, способствовать культурному и политическому многообразию ценностей при соблюдении приоритета на развитие, а не разрушение или порабощение, склонение к нищенству.

Справедливо, что не только Россия, но и многие государства в мире стремятся подняться в своем социально-экономическом развитии. «Объединенный Запад»

\footnotetext{
1 Лукьянов Ф. Игра в престолы. - Российская газета. 6.02. 2019.

2 По мнению известного политолога-международника С. Караганова, «мессианизм коммунизма или либерализма - скверный пережиток». См. Караганов С. Каким будет мир? - Российская газета. 15.02.2019. № 34. С. 9.

3 Там же.

4 Там же.

5 Давосский экономический форум состоялся 22-24 января 2019 г.
} 
мобилизуется в основном через экономические санкции и непрозрачную политику по отношению к России и другим защищающим свое национальное достоинство странам, стремится оказывать политическое, а также военное давление.

На Мюнхенской конференции в феврале 2019 г. организаторы встречи мировых политиков и экспертов обсуждали два выхода из новых реалий. Первый - смириться с новой эрой конкуренции великих держав, второй - сопротивляться переменам, объединившись вокруг США

Уточним, что Россия действует в русле декларируемой ее лидером политики ${ }^{2}$, в т.ч. используя авторитетные международные площадки. Так, в принятом не без трудностей итоговом документе саммита лидеров стран «Группы двадцати» в Аргентине в конце 2018 г. были обозначены общие подходы к решению проблем в мировой экономике, сфере безопасности и энергетике. Но ключевым вопросом оказалась поддержка позиции России о реформе Всемирной торговой организации $(\mathrm{BTO})^{3}$. Было также озвучено российское предупреждение о недопустимости «авантюрного использования» террористов в геополитических целях, т.к. «заигрывание с ними» побуждает их «совершать новые кровавые злодеяния» ${ }^{4}$. Сирийский опыт это подтвердил. За борьбу с односторонними и протекционистскими мерами коллективно выступали страны БРИКС (Бразилия, Россия, Индия, Китай и ЮАР), которые предложили наращивать взаимодействие и сотрудничество.

Однако применение в отношениях между странами «двойных стандартов» и ложных фактов для обвинений, привнесенное в политическую практику США и их сателлитами, удобно только им. Они стремятся продлевать любой ценой демонстрацию своей силы как «первенства» при стратегии использования «цветных революций», подлога и подкупа, ослабляя конкурентов. И это избранная ими стратегия и тактика действий при растущей мировой конкуренции старых режимов. Схема опробована ими во многих регионах и ныне применяется даже по отношению к ближайшим партнерам в Европе - Франции, Германии, а также применительно к целым регионам.

Разрастающаяся с каждым днем «стихийность» движения «желтых жилетов», потрясающих основы государственности пока во Франции, угрожает «поджечь» аналогичные протесты в соседней Бельгии других странах Европы. Начинающиеся протесты и народное возмущение все больше напоминают продуманную кампанию по смене руководства. Вся Европа замерла в определенном страхе, наблюдая за Пятой республикой 5 . Но местные СМИ, подробно описывая «бесчинства в Париже» и «радикализм желтых жилетов», ретушируют обвинительные интонации в адрес главных виновников - институтов и лидеров, которые привержены угасающей либеральной идеологии и политике 6 .

1 Интервью председателя Мюнхенской конференции Вольфганга Ишингера о центральном докладе. - Российская газета. 13.02.2019. С. 8.

2 Послание Президента РФ В.В. Путина Федеральному собранию. 20.02.2019.

3 Саммит: Взаимодействие лидеров «двадцатки» и мировая экономика были в центре повестки дня G-20 в Аргентине. Танго и кэш. - Российская газета. 03.12.2018. C. 1, 2.

4 Там же.

5 Руководитель Пятой республики Э. Макрон не скрывал претензий на лидирующие позиции в Евросоюзе, комплиментируя США и одновременно продвигая идею независимой от США общеевропейской армии. Он активно защищал ядерную сделку с Ираном, что вызывало возмущение, в том числе публичное, и американской администрации. Были и другие «прегрешения» французского президента, который не оценил предложенных ему в начале своей карьеры Д. Трампом дружеских объятий, посчитав их «удушающими». Поэтому у президента США к французскому коллеге «собрались для оплаты» сугубо личные счеты.

6 Если движение «желтых жилетов» отстранит Э. Макрона от власти, это существенно усилит американские позиции в Европе, дав понять другим лидерам стран ЕС, что с Трампом спорить, тем более конфликтовать, будет рискованно. 
Существует и наглядная угроза более слабым государствам, желающим сбросить «удушающий хомут американского центризма». Под видом гуманитарной помощи это демонстрируется в Венесуэле, других регионах. И здесь очевиден наглядный пример применения «двойных стандартов» и ложных обвинений, конкретного вмешательства «воли сильного» в дела суверенных государств. Поэтому хрестоматийный признак «цветных революций» - это наличие в них хорошо скрываемого североамериканского следа, который выражается в финансировании так называемых стихийных протестов. Их бенефициаром всегда становится Вашингтон, даже если на первый взгляд это не выглядит очевидным ${ }^{1}$.

Сегодня все активнее востребована стратегическая стабильность, за что выступает Россия и ее партнеры по БРИКС, другие страны. Поиск стратегической стабильности - это отказ от политики «двойных стандартов», стремление к углублению реформ без ущемления интересов других стран и народов при открытости и желании высококачественного развития.

Однако очевиден и космополитизм ${ }^{2}$ верхов западного мира во главе с США, который обусловливает также рост некоторой активности контрглобальной эволюции элит. Этот новый процесс стимулируется пробуксовыванием известного проекта глобализации. Он все заметнее терпит крах, т.к. использовался Альянсом вместе с США для решения лишь собственных задач и обогащения корпоративного и частного бизнеса. Он не отвечает интересам стран, идущих по пути развития, т.к. закабаляет тех, кто противостоит США. Кому-то навязывали его силой. Главной технологией глобализации более четверти века было тотальное доминирование США и опора на их финансы, применявшиеся современные коммуникации.

Партийные системы в большинстве стран Запада просто рассыпаются, потому что не соответствуют структуре социальных устремлений. Недавний опрос в Германии продемонстрировал показательную тенденцию, что правящая «большая коалиция» двух крупнейших и одной из старейших политических партий (христианские демократы и социал-демократы) сохраняет большинство только в одной возрастной категории - это люди свыше 65 лет. Во всех остальных группах населения консерваторы теряют вес, а социал-демократы уже выбыли из тройки основных политических сил в центре Германии. Такой диссонанс демонстрируется не только в Германии, но и в других странах ${ }^{3}$.

Майские (2019 г.) выборы в Европарламент грядут под знаком усиления радикализма в Европе. Здесь растет недоверие старым элитам. Но, например, «боевитые зеленые» в Германии не боятся идти против «правеющего» человеческого потока. А новая партия «Альтернатива для Германии» фактически уже этот поток возглавляет. Это уже запрос на влияние новых сил, даже в устоявшихся и считающихся респектабельными политических системах. Во Франции Э. Макрон, представлявший 1,5 года назад одну из ярких звезд новых элит, тоже не вписывается в новое восприятие обустраиваемого мира в Европе (даже его «элегантная эластичность оказывается не в чести»). Люди хотят определенности в гуманистической позиции, примеряя ее на себя, а не лоббирования дальнейшего обогащения олигархов.

В США после ноябрьских (2019 г.) выборов в конгресс демократы получили

1 Геополитика: Как во Франции развивают технологии «цветных революций». - Российская газета. 04.12.2018. C. 8.

2 Космополитизм выступает в различных социально-политических ориентациях широкого спектра, но в рассматриваемом контексте характеризует нигилистическое отношение к национальным традициям, культуре.

3 По материалам, публиковавшимся в СМИ в начале 2019 г. 
эффективный инструмент политического давления на «республиканского» президента. Но этого недостаточно, чтобы его «свалить». Блокирование и осложнение законодательной деятельности Белого дома можно отнести только к внутриполитической повестке, хотя оно сказывается и на обременении в политической деятельности. При этом Д. Трамп обрушивается на своих оппонентов, чтобы «сваливать» на них невыполнение тех или иных своих предвыборных обещаний. Демонстрируется тот же «двойной стандарт», но уже во внутригосударственных масштабах. При этом Д. Трамп рассматривает американскую политику в отношении России именно как функцию его внутренней борьбы.

Таковы сегодняшние метаморфозы существующего мира, где постепенно происходят стратегические сдвиги. Уточним, что через 35-40 лет после Второй мировой войны у руля государств находились люди, внутренне помнившие ее ужасы и действительно боявшиеся войны, особенно ее ядерного варианта. Еще недавно можно было посмеиваться над «брежневской эпохой» борьбы за мир (то есть, прежним поколением политиков). Но их действия сохранили мир. Сейчас у руля находятся внуки и правнуки воевавших. Страх войны у них ощутимо выветрился и напоминает реакцию на компьютерные игры. Поэтому воинственных заявлений становится все больше, а возникшая привычка к реальному миру, безобидным внешне играм в войну на компьютерах или по телевизору ослабили сопротивляемость ей. Запад, ныне являясь одним из нескольких игроков, в условиях наступления многополярной эры уже начал утрачивать внутреннее единство, создавая для России и ее партнеров новую ситуацию ${ }^{1}$. Тревожная неопределенность в умах элит, как и части масс, может лишь толкать к простым решениям. Это с одной стороны.

С другой - ситуация в последние 2-3 десятилетия усугубляется резким падением качества управляющих классов. Особенно это очевидно на Западе. Американская проблема очевидна... То же самое происходит в Европе: достаточно мысленно сравнить лидеров Старого Света 30-40-летней давности с сегодняшними ${ }^{2}$.

Один из результатов - усиление фактора дестабилизации в последние 1520 лет из-за перераспределения сил в мире. Ранее казалось, что объединенный Запад одержал окончательную победу (над «коммунизмом» - да). Но сегодня есть ощущение, что он находится в «злой обороне». Лозунг прошлых десятилетий: «как управлять подъемом новых» жизнь сегодня меняет на другой: «как управлять упадком старых». В этом временно́м интервале рухнули две глобалистские идеологии XX в. - коммунизм и либерализм. Вакуум быстро стал заполняться национализмом разного толка 3 .

Становится очевидным, что тенденция одновременно усиливается в связи с подъемом Азии. А это континент национальных государств. Здесь размораживаются старые или появляются новые конфликты: Японии - с соседями, Китая - с Индией, суннитских монархий - с Ираном и т.д. Более чем тревожна ситуация в военно-технической сфере. А серия нападений на страны, отказавшиеся от ядерного оружия (прежде всего, Ирак, Ливия), мощно усиливает позиции тех, кто хочет это оружие приобрести (боевики, террористы). Выход США г. из Договора по противоракетной обороне (2003 г.), и ныне - из ДРСМД (2019 г.) выбивает почву из-под прежнего режима нераспространения такого оружия. Уже началась крайне опасная гонка в сфере кибероружия,

\footnotetext{
1 Лукьянов Ф. Игра в престолы. - Российская газета. 06.02.2019. № 25.

2 Вывод, сформулированный в докладе «евромудрецов» в начале 2000 г: в Европе нет лидеров континентального масштаба.

3 Караганов С. Каким будет мир? - Российская газета. 15.02.2019. С. 9.
} 
которое у ряда государств имеет стратегический характер. А это не только потенциальная способность, а уже и инструмент разрушения экономик и обществ других государств.

Активно появляются новые страны-субъекты, создавшие и уже разворачивающие современное поколение неядерных вооружений, имеющих стратегический характер. Здесь стираются отличия между ядерной и обычной войной. При этом внушает тревогу начавшаяся волна роботизации вооружений с использованием искусственного интеллекта (стирается грань между войной и миром, ослабляется политический контроль и ответственность лидеров за свои действия).

Таким образом, можно отметить, что режим ограничения вооружений, созданный в 1970-1980 гг., имел некоторые изъяны. Но сам переговорный процесс между ведущими странами, обладающими военным арсеналом, не так явно провоцировал наращивание вооружений и военных расходов, хотя и действовал принцип накопления «козырей» для торга. Но паритет удавалось сохранять, и это самая важная победа в поддержании мира на планете.

Поэтому процесс ограничения вооружений был в целом полезен. Он способствовал улучшению политического климата, большей предсказуемости. Но этот процесс постепенно стал отмирать. Сначала НАТО отказалась модернизировать Договор об обычных вооруженных силах в Европе. Вооруженные силы и вооружение стран бывшего Варшавского договора оказались на его стороне. Смертельный удар по процессу был потом нанесен выходом США в 2003 г. из Договора по ПРО (договор был несущей основой всей концепции ограничения стратегических вооружений). Однако превосходство США получить не удалось. Россия была вынуждена модернизировать свои стратегические и околостратегические силы, создавая новое поколение систем с гарантией преодоления любой системы ПРО. Вопрос о наличии этих видов вооружения президент РФ В.В. Путин официально разъяснил в Послании Федеральному собранию 1 марта 2018 г. ${ }^{1}$

В этой непростой ситуации в мире становятся весьма востребованными действия по борьбе за мир. Это коренные общемировые интересы, которые никто защитить не сможет, если общественность мира не сплотится вокруг этой идеи. Здесь важны активная позиция и настрой на развитие многих народов.

Политическое руководство России имеет твердое стремление войти в пятерку ведущих стран. Она выступает за развитие конкуренции, но без разрушения культурных ценностей народов, хотя пока наша страна в целом (не отдельные ведущие регионы) характеризуется скорее динамикой социального выживания, чем устойчивого развития. Она находится на 59-м месте (из 152 учитываемых стран по рейтингу $S E D A)$ по индексу благополучия и устойчивого экономического развития ${ }^{2}$.

Уточним, что рейтинг $S E D A$ ежегодно составляется международной консалтинговой компанией The Boston Consulting Group (BCG). По итогам 2018 г. топ самых благополучных стран возглавила Норвегия. Вторую строчку заняла Швейцария, на 3-м месте расположилась Исландия ${ }^{3}$.

1 По оценкам специалистов, они упреждающе обесценивают гигантские капиталовложения США в гонку вооружения. Однако уже существует генетическое оружие, в т.ч. способное скрыто заражать семенной материал, вызывая катастрофическое падение урожая, падеж скота, и даже наносить вред этническим и социальным группам людей. Ведется и информационная война.

2 Методика SEDA разработана в 2012 г. как альтернатива прежним традиционным способам оценки экономического развития по динамике ВВП. Выявляется эффективность превращения валового национального дохода в благополучие населения вне зависимости от заработной платы.

3 В ходе оценки анализируются 10 параметров, включая экономическую стабильность, здравоохранение, образование и развитие инфраструктуры. 
Анализ свидетельствует, что рейтинг $S E D A$ традиционно продолжают возглавлять европейские державы. Отчасти это объясняется высоким уровнем доходов населения и целенаправленной поддержкой социального прогресса. Единственная страна, не принадлежащая к Старому Свету, но входящая в топ-10, - это Сингапур. 2-е в мире по плотности населения государство за последние годы совершило впечатляющий экономический скачок до уровня развитых стран, сделав ставку в государственной политике не на вооружение, а на образование и развитие человеческого капитала ${ }^{1}$.

Вместе с тем за последнее десятилетие Россия продвинулась вперед по большинству параметров, особенно в области инфраструктуры и экономической стабильности ${ }^{2}$. Страны из топ-30 Россия превосходит по уровню занятости. В сравнении с другими участниками БРИКС (Бразилия, Индия, Китай, ЮАР) она имеет хорошие показатели гендерного равенства и развития гражданского общества.

Уточним, что стратегическому партнеру России, в т.ч. по БРИКС, Китаю благодаря удачным реформам и политике открытости удалось одержать серьезную победу над коррупцией. Так, лидер страны Си Цзиньпин заявил: «...проявляя жесткий подход к соблюдению партийной дисциплины, нулевую терпимость к проявлениям разложения в партии, формализму, бюрократии и расточительству, была одержана решительная победа над коррупцией» 3 .

Но несмотря на жесткость и дисциплину Китай расширяет «открытость» и желание «продвигать создание сообщества единой судьбы человечества». Он остается приверженцем создания открытой мировой экономики и намерен противостоять гегемонизму в международных отношениях. Смысл этого движения - превратиться в «повсеместно признанного строителя международного мира, вносящего вклад в глобальное развитие, в защитника мирового порядка» 4 .

Партнерство России со своим соседом Китаем дает дополнительное объективное осознание положения страны и, учитывая возросший в последние годы потенциал, возможность проводить более целенаправленный курс на улучшение социального положения россиян и достижение значительного экономического роста за счет современного модернизационного ресурса.

\footnotetext{
1 Россия сохраняет свою позицию в рейтинге в течение последних 5 лет. Ближайшими соседями России в этом году стали Грузия (60-е место) и Аргентина (58-е). Коэффициент SEDA России составляет 1,11, тогда как в среднем по миру он равен 1,0.

2 Международное рейтинговое агентство Moody's в начале февраля 2019 г. повысило суверенный рейтинг России со спекулятивного уровня Вa1 до инвестиционного Ваa 3 со стабильным прогнозом. То есть, все 3 главных рейтинговых агентства, включая $S \& P$ и Fitsh, признали Россию инвестиционной страной, в т.ч. с правом эмитента в иностранной и национальной валюте и в сфере высокого рейтинга приоритетного необеспеченного долга.

3 Согласно китайской статистике, с момента его прихода к власти за нарушение партийной дисциплины и коррупцию были наказаны около 1,5 млн чиновников.

${ }^{4}$ Из выступления Си Цзиньпина на юбилейных мероприятиях, посвященных 40-летию китайских реформ.
} 
BAKUSHEV Valery Vladimirovich, Dr.Sci. (Pol.Sci.), Professor; Head of the Chair of Parliamentarism and Interparliamentary Cooperation, Institute of Public Service and Management - the Branch of Russian Presidential Academy of National Economy and Public Administration (RANEPA) (82 Vernadskogo Ave, Moscow, Russia, 119571; la.kolesnikova @igsu.ru)

PONEDELKOV Aleksandr Vasil'evich, Dr.Sci. (Pol.Sci.), Professor; Head of the Chair of Political Science and Ethnopolitics, South Russian Institute of Management - Brunch of the Russian Presidential Academy of National Economy and Public Administration (RANEPA)(70 Pushkinskaja St, Rostov-on-Don, Russia, 344002; ponedelkov@uriu. ranepa.ru)

\title{
SEARCHING FOR STRATEGIC STABILITY WITH RUSSIA'S PARTICIPATION: REJECTION OF DOUBLE STANDARDS AND POLITICAL LIES
}

\begin{abstract}
The article shows that the actual problem is not in only searching, but also in explanation of the existing hypertrophied conflict. The ongoing reformatting of world processes is causing a security breach. They are due to a new era of competition between the great powers (The Munich Security Conference among the Superpowers in 2019 attributed Russia as one of them along with the United States and China and recognized that any European or global security is impossible without Russia). However, the understanding that the emerging new multipolar world order does not solve all the problems is still unstable. It only creates a new environment to solve them. There are no fewer bleeding conflicts. At the same time, the structure of political parties in the Old World and new democracies does not express the modern interest of the majority of citizens. The article raises the problem and reveals the position of the author on the search for strategic stability with the participation of Russia, as it has already emerged from the niche of humiliating country and seeking to enter the top five countries of the world.

Keywords: current crisis in geopolitics, tacit support of Nazism in Europe, ambitions of United States to maintain its hegemony, split position in EU, strengthening political positions of Russia for strategic stability, new appeal to struggle for peace, Russia's policy on partnership, novelty of the domestic socio-economic policy
\end{abstract}

